Research Article

\title{
Thermophoresis and Brownian Model of Pseudo-Plastic Nanofluid Flow over a Vertical Slender Cylinder
}

\author{
Faizan Hussain (D), ${ }^{1}$ Azad Hussain $\left(\mathbb{D},{ }^{1}\right.$ and Sohail Nadeem ${ }^{2}$ \\ ${ }^{1}$ Department of Mathematics, University of Gujrat, Gujrat 50700, Pakistan \\ ${ }^{2}$ Department of Mathematics, Quaid-I-Azam University, Islamabad 44000, Pakistan \\ Correspondence should be addressed to Faizan Hussain; hussainfaizan8@gmail.com
}

Received 20 April 2020; Revised 2 July 2020; Accepted 24 July 2020; Published 14 August 2020

Guest Editor: Cuimei Jiang

Copyright (c) 2020 Faizan Hussain et al. This is an open access article distributed under the Creative Commons Attribution License, which permits unrestricted use, distribution, and reproduction in any medium, provided the original work is properly cited.

\begin{abstract}
This study focuses on the industrial and engineering interest quantities, such as drag force and rate of transmission of heat, for pseudo-plastic nanofluid flow. The attributes of natural convection of the pseudo-plastic nanofluid flow model over a vertical slender cylinder are explored. The pseudo-plastic flow is studied under the influence of concentration of nanoparticles, rate of heat transmission, and drag force. For the first time, the pseudo-plastic nanofluid flow model has been implemented over a vertical slender cylinder which is not yet investigated. The acquired model is based on thermophoresis and Brownian motion mechanisms. The governing equations of pseudo-plastic nanofluid in cylindrical coordinates are modelled. The developed system of nonlinear equations is tackled by boundary layer assumptions and similarity transformations. Moreover, the solution of the acquired system exhibited by using a new powerful numerical technique. A comprehensive debate on drag force and transmission of heat under the influence of various emerging parameters is illustrated in the table. Furthermore, the effects of dimensionless parameters over the velocity profile, temperature profile, and concentration of nanoparticle profile have been exhibited graphically.
\end{abstract}

\section{Introduction}

Investigation of the non-Newtonian fluids gains prodigious attention of researchers over a half-century because naturally, most of the fluids used in the industrial applications are non-Newtonian fluids. This is the main cause of increased applications of non-Newtonian fluids in the industrial field and engineering such as petroleum production, molten plastics, food engineering, automobiles, polymer solution industry, chemical engineering, and power engineering. A solitary established equations cannot pronounce the attributes of such non-Newtonian fluids because these kinds of fluids have a nonlinear relationship among the rate of stress and strain. Therefore, several scientists and engineers have pronounced models for non-Newtonian fluids [1-10]. Ellahi et al. [11] explored thermally charged MHD biphase flow coating with non-Newtonian nanofluid over the slippery walls. The sustainable features of MHD Jaffrey fluid for biobi-phase flow are carried out by Zeeshan et al. [12]. Rehman et al. [13] examined MHD flow of the nanoparticle influenced near a stagnation point over an exponential stretched surface. Parand et al. [14] described the boundary layer flow of Powell-Eyring fluid for a stretching sheet. Generation/ absorption of heat through the flow of axisymmetric Casson fluid over a stretched cylinder is addressed by Javed et al. [15]. Additional appropriate studies in this way are in $[16,17]$.

Over the last few years, we have adopted a pioneering procedure for refining the transmission of heat by utilizing ultrafine solid particles in the fluids, and these particles have been used widely called as nanofluid. The label "nanofluid" was used for the first time in 1995 by Choi and Eastman [18]. He cited that it is conceivable to boost convection of transmission of heat and thermal conductivity efficiency by using nanofluids. To handle nanofluids, Buongiorno [19] introduced a mathematical model and explored numerous transport mechanisms and applications about the nanofluids. Miscellaneous purposes of nanofluids have been 
uncovered by Das et al. [20]. Zhang et al. [21] scrutinized the nanofluid for MHD radiative flow over a variable heat flux and chemical reaction surface. Transport of heat for the ferromagnetic fluid with thermal stratification over a stretching sheet was examined by Muhammad et al. [22]. Saini and Sharma [23] extended the application of nanofluids through the investigation of double-diffusive bioconvection. Further extensive research and applications of nanofluids across numerous fields are heat transmission, energy, microequipment, and boiling applications [24-28].

Williamson's fluid model has non-Newtonian behaviour in nature like pseudo-plastic fluid which defines the flow of shear thinning. The industrial, engineering, and biological fluids which observe as Williamson's fluid are blood, glue, paint, ketchup, polymer solutions, and nail polish. Williamson [29] who discovered the model to communicate pseudo-plastic attributes along with features of extreme points of viscosity. Due to this invention, innovated researchers are motivated to discover more upfront classifications of non-Newtonian fluid. Ramzan et al. [30] analyzed the numerical solution of MHD flow over a stretched surface with convective boundary conditions using the shooting method. Two-dimensional flow of Williamson's fluid film with heat diffusion under the influence of thermal radiation was inspected via an optimal approach by Shah et al. [31].

Rate of transmission of heat, the transmission of mass rate, and skin friction coefficient play a dynamic character during coating of wires or polymer fibre coating. As wires have a thin cylindrical shape, miscellaneous researchers have launched several mathematical models. In axial incompressible flow, Seban and Bond [32] premeditated the attributes of drag force and rate of transmission of heat for a cylinder in 1951. Under the uniform surface heat flux, Mucoglu and Chen [33], for the first time, scrutinized the slender cylinder with the help of mixed convection regime. Nadeem et al. [34] analyzed the boundary layer flow and transmission of heat of a nanofluid in a vertical slender cylinder. Patil et al. [35] examined the mixed convection nanofluid boundary layer flow under the effect of surface roughness with a moving slender cylinder. Reddy et al. [36] explored the natural convection for the Casson fluid flow past over a hollow slender cylinder. With the help of Bejan's heat function concept, Reddy et al. [37] investigated the unsteady MHD micropolar fluid flow in a homogeneously thermal radiative hollow slender cylinder with the radiative transmission of heat effect. Further latest stimulating work in this area can be found in [38-42].

The literature review replicates that, generally, the researchers engaged themselves to study non-Newtonian fluids' behaviour by assuming different effects. The attributes of natural convection of Williamson's nanofluid model over a vertical slender cylinder are not explored until now. Therefore, the developed model is simplified by the boundary layer approximation and similarity transformations. The governing coupled nonlinear system of equations is then solved by a new powerful numerical technique. Furthermore, physical behaviour for the industrial interests of the fluid will be examined through the table.

\section{Analysis of Flow and Mathematical Formulation}

Suppose an incompressible Williamson's nanofluid flow along with a permeable vertical slender cylinder with radius $a$ having uniform ambient temperature $T_{\infty}$. The coordinates $(x, r)$ are used, whereas $x$ is acting along the surface of the cylinder and $r$ along the radial direction. The velocity profile, temperature profile, and concentration profile are as follows:

$$
\begin{aligned}
V(x, r) & =(w, 0, u), \\
T & =T(x, r), \\
\phi & =\phi(x, r),
\end{aligned}
$$

where $(w(x, r), u(x, r))$ are velocity components along the surface and radial direction. The boundary layer equations of motion, energy, and the nanoparticle concentration are

$$
\begin{aligned}
\frac{\partial}{\partial r}(r w)+r \frac{\partial u}{\partial x}= & 0 \\
u \frac{\partial u}{\partial x}+w \frac{\partial u}{\partial r}= & -\frac{1}{\rho} \frac{\partial p}{\partial x}+v\left(\frac{\partial^{2} u}{\partial r^{2}}+\frac{1}{r} \frac{\partial u}{\partial r}+\Gamma \frac{1}{r \sqrt{2}}\left(\frac{\partial u}{\partial r}\right)^{2}\right. \\
& \left.+\sqrt{2} \Gamma \frac{\partial^{2} u}{\partial r^{2}} \frac{\partial u}{\partial r}\right)+\left(\frac{\left(\rho^{*}-\rho\right)\left(\phi-\phi_{\infty}\right)}{\rho}\right. \\
& \left.+\left(1-\phi_{\infty}\right)\left(T-T_{\infty}\right) \beta_{\mathrm{th}}\right) g_{\mathrm{gr}}, \\
w \frac{\partial T}{\partial r}+u \frac{\partial T}{\partial x}= & \alpha\left(\frac{\partial^{2} T}{\partial r^{2}}+\frac{1}{r} \frac{\partial T}{\partial r}\right)+\frac{\rho^{*} c_{p}^{*}}{\rho c_{p}}\left(D_{B} \frac{\partial \phi}{\partial r} \frac{\partial T}{\partial r}\right. \\
& \left.+\frac{D_{T}}{T_{\infty}}\left(\frac{\partial T}{\partial r}\right)^{2}\right), \\
w \frac{\partial \phi}{\partial r}+u \frac{\partial \phi}{\partial x}= & D_{B}\left(\frac{\partial^{2} \phi}{\partial r^{2}}+\frac{1}{r} \frac{\partial \phi}{\partial r}\right)+\frac{D_{T}}{T_{\infty}}\left(\frac{\partial^{2} T}{\partial r^{2}}+\frac{1}{r} \frac{\partial T}{\partial r}\right)
\end{aligned}
$$

The accompanied boundary conditions are

$$
\begin{aligned}
& u(x, a)=0, \\
& T(x, a)=T_{w}(x), \\
& u(x, r) \longrightarrow U(x), \quad \text { as } r \longrightarrow \infty, \\
& T(x, r) \longrightarrow T_{\infty}, \quad \text { as } r \longrightarrow \infty, \\
& \phi(x, a)=\phi_{w}(x), \quad \\
& \phi(x, r) \longrightarrow \phi_{\infty}, \quad \text { as } r \longrightarrow \infty .
\end{aligned}
$$

Here, $U(x)=(x / l) U_{\infty}$ is the mainstream velocity, $v$ is called kinematic viscosity and is defined as $v=(\mu / \rho), \Gamma>0$ articulated the material constant for Williamson's fluid, and $\rho$ denotes the density of the fluid. Now, the nondimensional variables and similarity transformations are defined as follows: 


$$
\begin{aligned}
& u=U_{\infty}\left(\frac{x}{l}\right) f^{\prime}(\eta), \\
& w=-\frac{a}{r}\left(\frac{v U_{\infty}}{l}\right)^{(1 / 2)} f(\eta), \\
& \theta=\frac{T-T_{\infty}}{T_{w}-T_{\infty}} \\
& \psi=\frac{\phi-\phi_{\infty}}{\phi_{w}-\phi_{\infty}} \\
& \eta=\frac{r^{2}-a^{2}}{2 a}\left(\frac{U_{\infty}}{v l}\right)^{(1 / 2)}
\end{aligned}
$$

in which $T_{w}-T_{\infty}=\Delta T(x / l)$ and $\phi_{w}-\phi_{\infty}=\Delta \phi(x / l)$ operated for the characteristic temperature $\Delta T$ and nanoparticle concentration $\Delta \phi$. By using the above transformations, equation (2) is identically satisfied, and equations (3)-(5) will be articulated as

$$
\begin{aligned}
& \left(2 \eta \gamma_{c}+1\right) f^{\prime \prime \prime}+2 \gamma_{c} f^{\prime \prime}+3 \lambda \gamma_{c}\left(2 \eta \gamma_{c}+1\right)^{(1 / 2)} f^{\prime \prime 2} \\
& +2 \lambda\left(2 \eta \gamma_{c}+1\right)^{(3 / 2)} f^{\prime \prime} f^{\prime \prime \prime}+f f^{\prime \prime}-f^{\prime 2} \\
& \quad+\lambda_{N}\left(1-\phi_{\infty}\right)\left(\theta+N_{r} \psi\right)+1=0, \\
& \left(2 \eta \gamma_{c}+1\right) \theta^{\prime \prime}+2 \gamma_{c} \theta^{\prime}+\operatorname{Pr}\left(f \theta^{\prime}+f^{\prime} \theta\right)+\left(2 \eta \gamma_{c}+1\right) \\
& \cdot\left(T_{\mathrm{p}} \theta^{\prime 2}+B_{\mathrm{p}} \theta^{\prime} \psi^{\prime}\right)=0, \\
& \left(2 \eta \gamma_{c}+1\right) \psi^{\prime \prime}+2 \gamma_{c} \psi^{\prime}+\operatorname{PrLe}\left(f \psi^{\prime}-f^{\prime} \psi\right)+\frac{T_{\mathrm{p}}}{B_{\mathrm{p}}} \\
& \cdot\left[\left(2 \eta \gamma_{c}+1\right) \theta^{\prime \prime}+2 \gamma_{c} \theta a^{\prime}\right]=0 .
\end{aligned}
$$

Dimensionless attached boundary conditions are

$$
\begin{aligned}
f(0) & =c_{0}, \\
f^{\prime}(0)= & 0, \\
& f^{\prime} \longrightarrow 1, \quad \text { as } \eta \longrightarrow \infty, \\
\theta(0) & =1, \\
\psi(0) & =1, \\
& \longrightarrow 0, \quad \\
& \longrightarrow 0, \quad \text { as } \eta \longrightarrow \infty,
\end{aligned}
$$

where $\gamma_{c}=\sqrt{v l / U_{\infty} a^{2}}$ illustrates the curvature parameter, $\lambda=\left(\Gamma x U^{(3 / 2)}\right) /\left(\sqrt{2 v} l^{(3 / 2)}\right)$ symbolizes Williamson's dimensionless parameter, $\lambda_{N}=\left(l \Delta T g_{\mathrm{gr}} \beta_{\mathrm{th}}\right) / U_{\infty}^{2}$ pronounces as the parameter of natural convection, $N_{r}=$ $\left(\left(\phi_{w}-\phi_{\infty}\right)\left(\rho^{*}-\rho\right)\right) /\left(\rho \beta_{\text {th }}\left(1-\phi_{\infty}\right)\left(T_{w}-T_{\infty}\right)\right)$ means the buoyancy ratio, $\operatorname{Pr}=v / \alpha$ is identified as the Prandtl number, $B_{\mathrm{p}}=\left(\rho^{*} c_{p}^{*} D_{B}\left(\phi_{w}-\phi_{\infty}\right)\right) /\left(\rho c_{p} \alpha\right)$ stands for the Brownian motion parameter, $T_{\mathrm{p}}=\left(\rho^{*} c_{p}^{*} D_{T}\left(T_{w}-T_{\infty}\right)\right) /\left(\alpha T_{\infty} \rho c_{p}\right)$ corresponds to the thermophoresis parameter, and $\mathrm{Le}=\alpha / D_{B}$ is known as the Lewis number.

\section{Physical Quantities of the Industrial Interest}

For the industrial interest, the physical quantities, i.e., drag force and transmission of heat, are stated as

$$
\begin{aligned}
C_{f} & =\frac{s_{\mathrm{w}}}{(1 / 2) \rho U^{2}}, \\
\mathrm{Nu} & =\frac{x q_{\mathrm{w}}}{\alpha_{\infty}\left(T_{\mathrm{w}}-T_{\infty}\right)},
\end{aligned}
$$

where $s_{\mathrm{w}}$ stands for the shear stress tensor over the surface of the slender cylinder, while $q_{\mathrm{w}}$ is called wall heat flux. These physical quantities can be articulated as

$$
\begin{aligned}
& s_{\mathrm{w}}=\mu\left(\frac{\partial u}{\partial r}+\frac{\Gamma}{\sqrt{2}}\left(\frac{\partial u}{\partial r}\right)^{2}\right)_{r=a}, \\
& q_{\mathrm{w}}=-\alpha_{\infty}\left(\frac{\partial T}{\partial r}\right)_{r=a} .
\end{aligned}
$$

According to similarity transformation, equation (15) is transformed as

$$
\begin{aligned}
& \frac{1}{2} C_{f} \operatorname{Re}^{(1 / 2)}=f^{\prime \prime}(0)+\lambda f^{\prime \prime}(0)^{2}, \\
& \operatorname{NuRe}^{-(1 / 2)}=-\theta^{\prime}(0) .
\end{aligned}
$$

\section{Numerical Solution}

The solution of the nonlinear system of ODEs (10)-(12) over the accompanied condition equations (13) and (14) is tackled through the numerical algorithm of MATLAB inherent scheme bvp4c. In order to apply this scheme, first of all, higher-order differential equations are transformed into first-order ODEs. The procedure is as follows.

Let us suppose that

$$
\begin{aligned}
f(\eta) & =y_{1}(x), \\
f^{\prime}(\eta) & =y_{2}(x), \\
f^{\prime \prime}(\eta) & =y_{3}(x), \\
f^{\prime \prime \prime}(\eta) & =y_{3}^{\prime}(x), \\
\theta(\eta) & =y_{4}(x), \\
\theta^{\prime}(\eta) & =y_{5}(x), \\
\theta^{\prime \prime}(\eta) & =y_{5}^{\prime}(x), \\
\psi(\eta) & =y_{6}(x), \\
\psi^{\prime}(\eta) & =y_{7}(x), \\
\psi^{\prime \prime}(\eta) & =y_{7}^{\prime}(x) .
\end{aligned}
$$
follows: Therefore, equations (10)-(14) are transformed as 


$$
\begin{aligned}
& y_{3}^{\prime}(x)=\frac{\left(-2 \gamma_{c} y_{3}-3 \lambda \gamma_{c}\left(1+2 x \gamma_{c}\right)^{(1 / 2)}\left(y_{3}\right)^{2}-y_{1} y_{3}+\left(y_{2}\right)^{2}-\lambda_{N}\left(1-\phi_{\infty}\right)\left(y_{4}+N_{r} y_{6}\right)-1\right)}{\left(1+2 x \gamma_{c}\right)+2 \lambda\left(1+2 x \gamma_{c}\right)^{3 / 2} y_{3}(x)}, \\
& y_{5}^{\prime}(x)=\frac{-2 \gamma_{c} y_{5}-\operatorname{Pr}\left(y_{1} y_{5}+y_{2} y_{4}\right)-\left(1+2 x \gamma_{c}\right)\left(B_{p} y_{5} y_{7}+T_{p} y_{5}^{2}\right)}{\left(1+2 x \gamma_{c}\right)} \\
& y_{7}^{\prime}(x)=-2 \gamma_{c} y_{7}-\operatorname{LePr}\left(y_{1} y_{7}-y_{2} y_{6}\right)-\left(\frac{\left.T_{\mathrm{p}} / B_{c}\right)\left[\left(1+2 x \gamma_{c}\right) y_{5}^{\prime}+2 \gamma_{c} y_{5}\right]}{\left(1+2 x \gamma_{c}\right)}\right.
\end{aligned}
$$

with conditions

$$
\begin{aligned}
y_{1}(0)-c_{0} & =0, \\
y_{2}(0) & =0, \\
y_{2}(\infty)-1 & =0, \\
y_{4}(0)-1 & =0, \\
y_{5}(\infty) & =0, \\
y_{6}(0)-1 & =0, \\
y_{7}(\infty) & =0 .
\end{aligned}
$$

\section{Discussion}

Natural convection of Williamson's nanofluid over a slender cylinder has been analyzed. Numerical solution is obtained by using MATLAB scheme bvp4c. Physical properties of the nanofluid are portrayed by using the Buongiorno model. Likewise, transmission of heat and mass is differentiated by means of assorted parameters.

\subsection{Velocity Profiles}

5.1.1. Attributes of $\gamma_{c}$ and $\lambda$ for $f^{\prime}(\eta)$. Figures (1) and (2) show the attributes of curvature parameter $\gamma_{\mathrm{c}}$ and Williamson's dimensionless parameter $\lambda$ for $f^{\prime}(\eta)$. It is well defined from Figures (1) and (2) that intensifying the values of $\gamma_{\mathrm{c}}$ tends to devalue $f^{\prime}(\eta)$; however, equivalent behaviour is anticipated for Williamson's parameter $\lambda$. This is because after intensifying the curvature parameter $\gamma_{c}$, the radius of the cylinder with the fluid declines. Similarly, after intensifying Williamson's parameter $\lambda$ which will cause a decline in velocity because fluid opposes more resistance.

5.1.2. Attributes of $\lambda_{N}$ and $N_{r}$ for $f^{\prime}(\eta)$. The attribution of $\lambda_{\mathrm{N}}$ and $N_{\mathrm{r}}$ is shown in Figures (3) and (4). From Figures (3) and (4), it defines that, by intensifying natural convection $\lambda_{\mathrm{N}}$ and buoyancy ratio $N_{\mathrm{r}}$, the buoyancy force will cause the higher velocity attained by the fluid.

\subsection{Temperature Profiles}

5.2.1. Attributes of $\gamma_{c}$ and $\operatorname{Pr}$ for $\theta(\eta)$. The behaviour of temperature profile $\theta(\eta)$ for distinct values of curvature parameter $\gamma_{c}$ and Prandtl number is reported in Figures (5) and (6). Evidently, from Figure 5, it can be described that enhancement in the curvature parameter yields intensifying in $\theta(\eta)$. Moreover, in Figure 6, the temperature profile and the boundary layer thickness decrease due to enhancement in Prandtl number (Pr). Which uncovers the truth that, enlarging in $\mathrm{Pr}$ cause the reduction in the thermal diffusivity of the fluids accordingly.

5.2.2. Attributes of $T_{p}$ and $B_{p}$ for $\theta(\eta)$. The contribution of thermophoresis parameter $T_{\mathrm{p}}$ and Brownian motion $B_{\mathrm{p}}$ is described in Figures (7) and (8). Evidently, larger $T_{\mathrm{p}}$ and $B_{\mathrm{p}}$ produce higher $\theta(\eta)$. Practically, movement of a small number of particles from higher temperature to the lower one is defined as the thermophoresis phenomenon. Hence, a greater number of nanoparticles are shifted from the hot region which raises the fluid temperature. However, due to the increase in Brownian motion parameter $B_{\mathrm{p}}$ in the result, random motion of the nanoparticles will be raised which causes intensifying in the temperature of the fluid.

\subsection{Concentration Profiles}

5.3.1. Attributes of $\psi(\eta)$ on $\gamma_{c}$. Figure 9 exhibits the consequences of curvature parameter $\gamma_{c}$ on nanoparticle concentration $\psi(\eta)$. It is clear from the figure that intensifying curvature parameter $\gamma_{\mathrm{c}}$ diminishes the nanoparticle concentration of the fluid. According to the industrial view, after increase in the curvature parameter, it caused the reduction in the radius of the slender cylinder; hence, concentration of nanoparticles also reduced.

5.3.2. Attributes of Lewis Number Le and Prandtl Number on $\psi(\eta)$. The behaviour of Lewis number Le is depicted for $\psi(\eta)$ through Figure 10. It is scrutinized that $\psi(\eta)$ is diminished by increasing Lewis number Le. Physically, due to the levitation of diffusivity of heat and mass, nanoparticle concentration $\psi(\eta)$ diminished. Furthermore, scrutinization of the attribution of Prandtl number Pr for $\psi(\eta)$ is portrayed through Figure 11. Physically, intensifying in Prandtl number will cause the more heat convection occur because thickness of the thermal boundary layer is greater than the velocity boundary layer. Hence, nanoparticle concentration diminished.

5.3.3. Attributes of $T_{p}$ and $B_{p}$ on $\psi(\eta)$. The impact of thermophoresis parameter $T_{\mathrm{p}}$ and Brownian motion parameter $B_{\mathrm{p}}$ on $\psi(\eta)$ is depicted in Figures (12) and (13). Due 


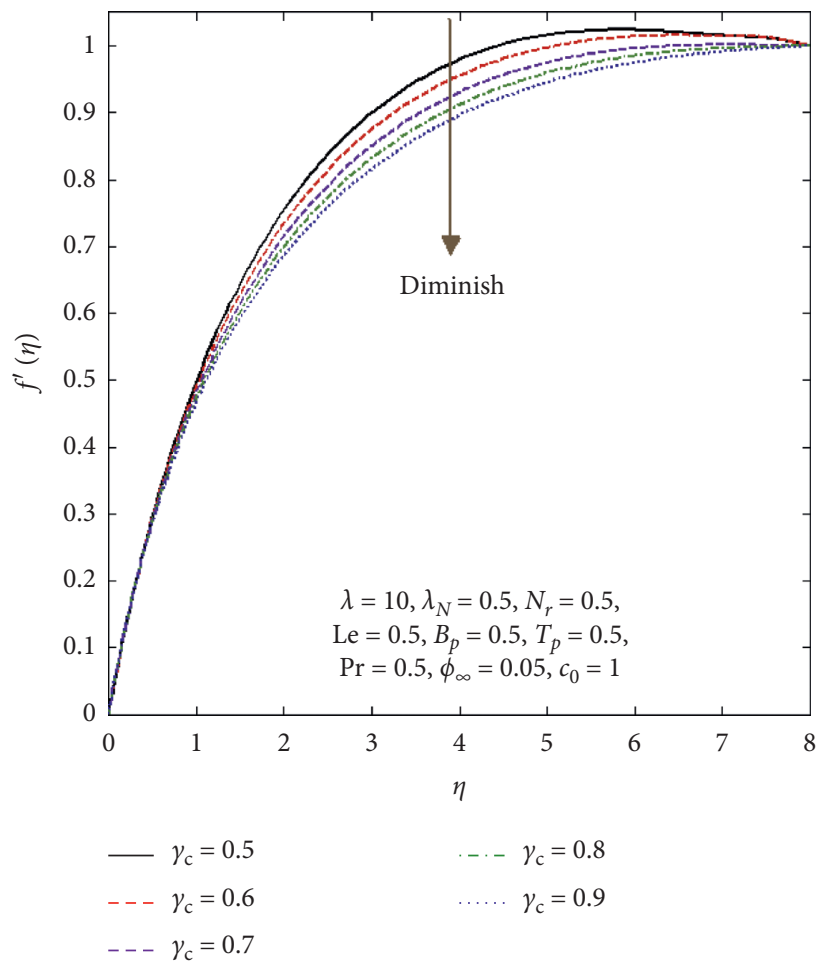

Figure 1: Consequences for $\gamma_{\mathrm{c}}$ on $f^{\prime}(\eta)$.

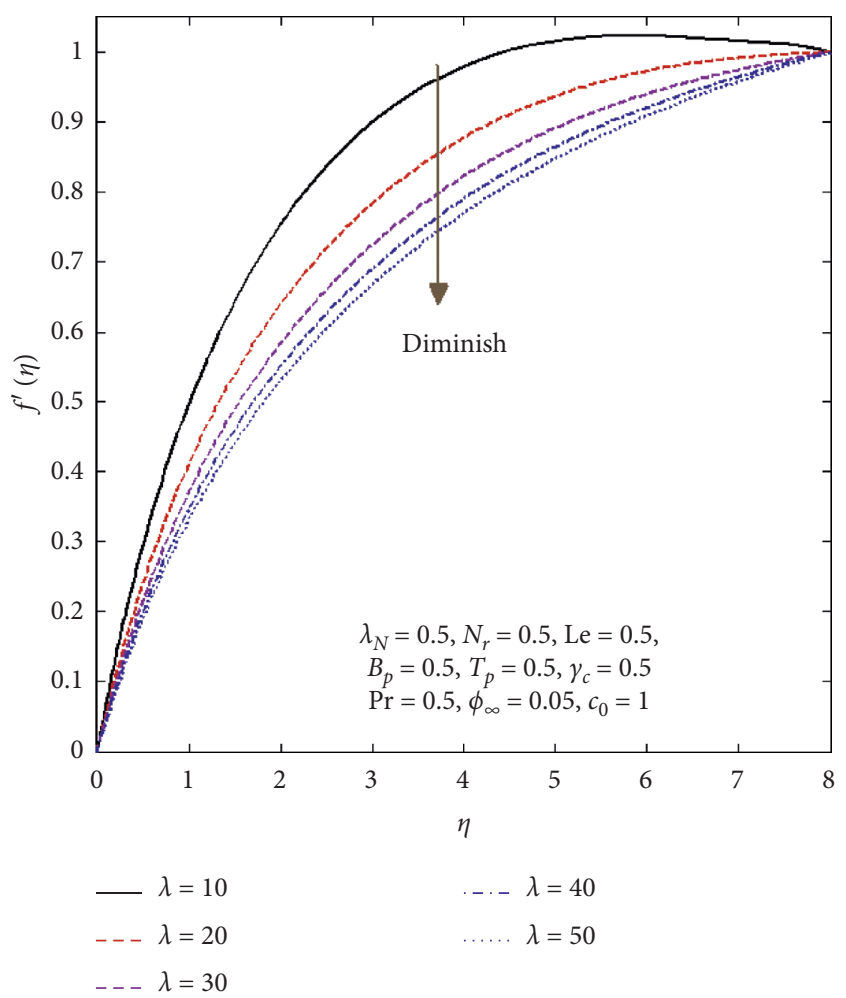

Figure 2: Consequences for $\lambda$ on $f^{\prime}(\eta)$.

to the increase of $T_{p}$, boundary layer thickness of nanoparticle concentration intensified. As a matter of fact, thermophoresis force increases for higher estimation of $T_{\mathrm{p}}$, which yields nanoparticle relocations from higher to lower

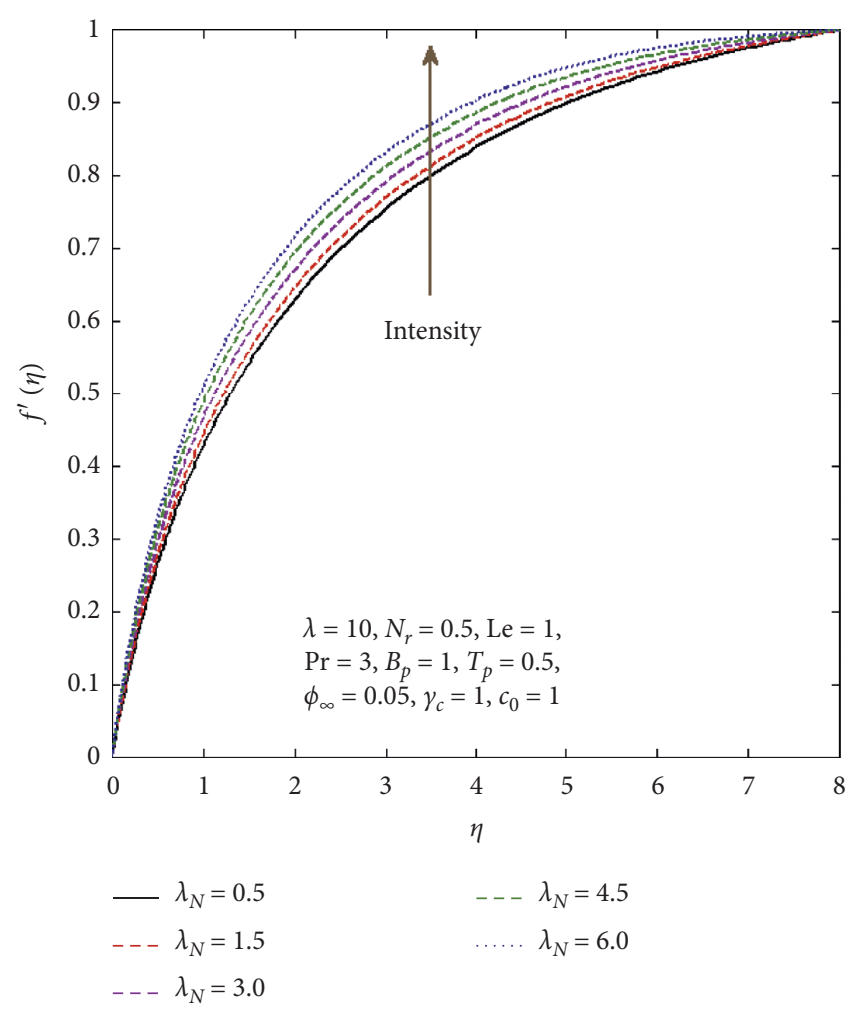

Figure 3: Consequences for $\lambda_{N}$ on $f^{\prime}(\eta)$.

temperature; hence, $\psi(\eta)$ intensifies (see Figure 12). However, $\psi(\eta)$ and its concentration boundary layer diminish when $B_{\mathrm{p}}$ is amplified (see Figure 13). 


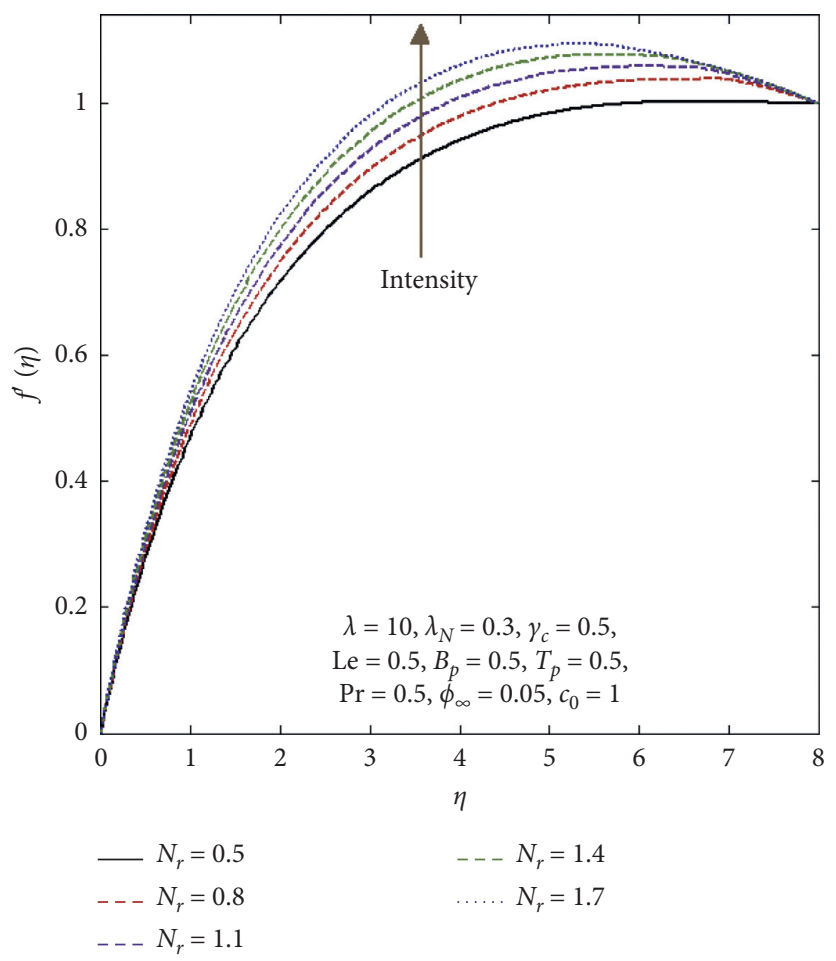

Figure 4: Consequences for $N_{\mathrm{r}}$ on $f^{\prime}(\eta)$.

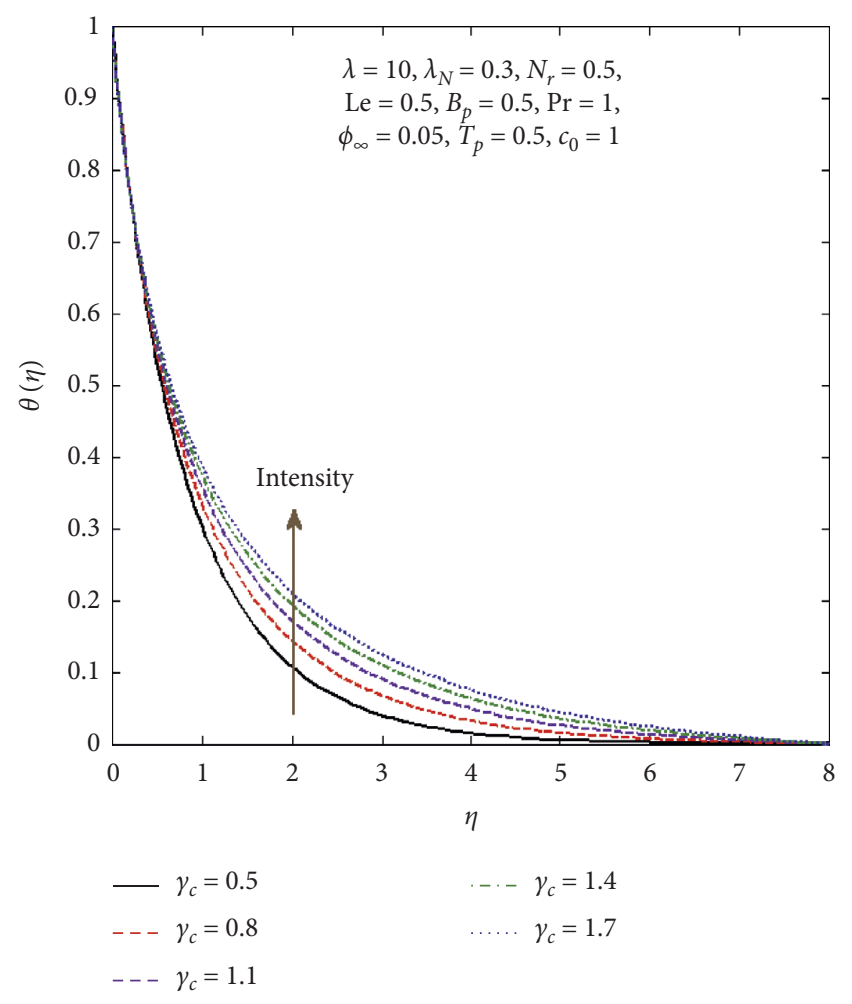

FIgURE 5: Consequences for $\gamma_{\mathrm{c}}$ on $\theta(\eta)$.

5.4. Attributes of Drag Force and Rate of Transmission of Heat. The attributes of physical parameters such as curvature parameter $\gamma_{c}$, Williamson's parameter $\lambda$, natural convection

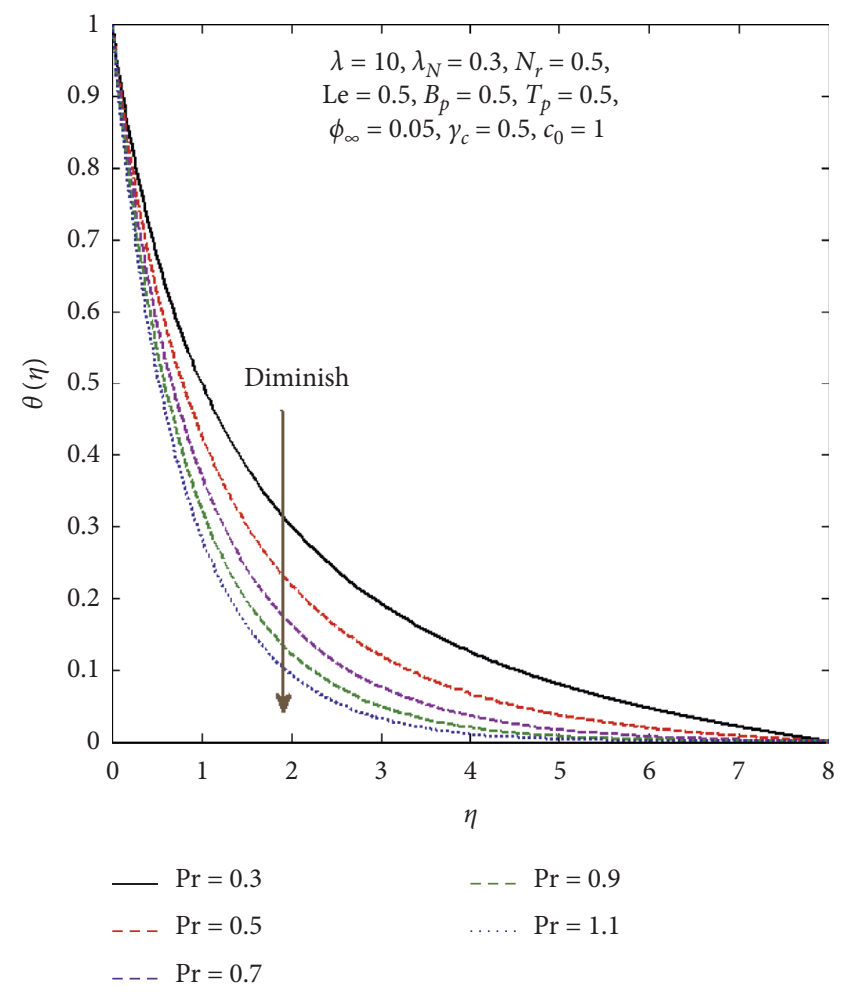

Figure 6: Consequences for $\operatorname{Pr}$ on $\theta(\eta)$.

$\lambda_{N}$, and buoyancy ratio $N_{r}$ on drag force are exhibited in Table 1 . It is evidently clear from the table that drag force is intensified by enhancing $\gamma_{c}, \lambda, \lambda_{N}$, and $N_{\mathrm{r}}$. Table 2 expresses the behaviour of physical parameters on the rate of 


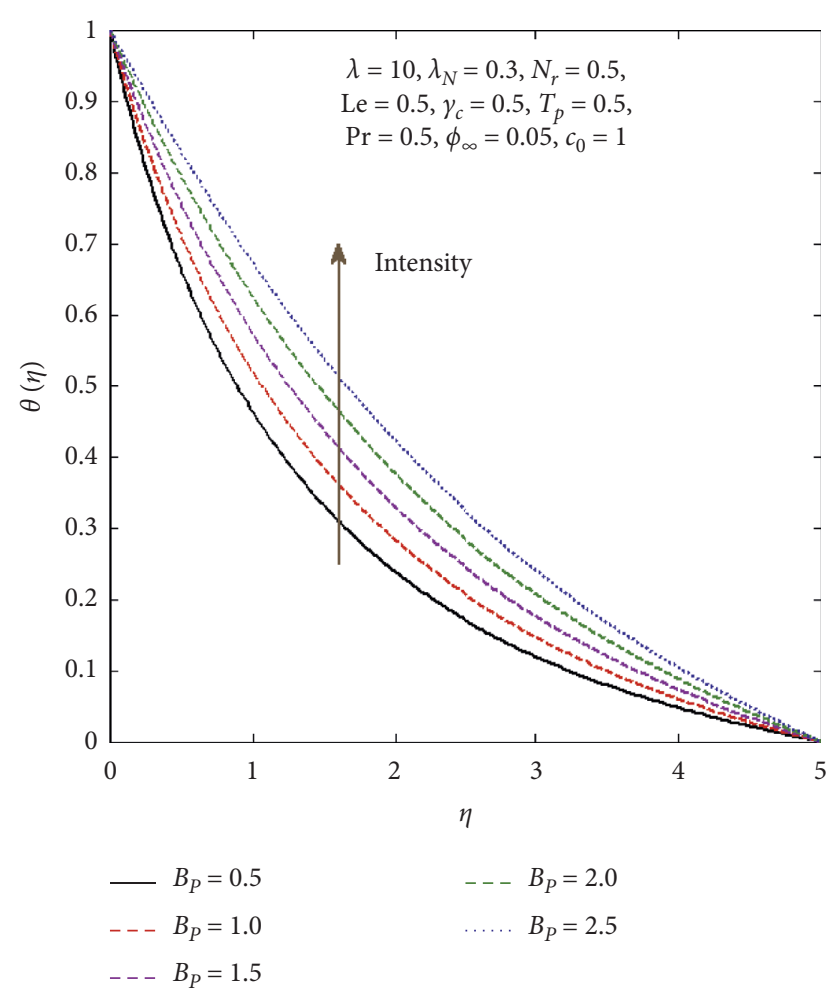

FIgURe 7: Consequences for $T_{\mathrm{p}}$ on $\theta(\eta)$.

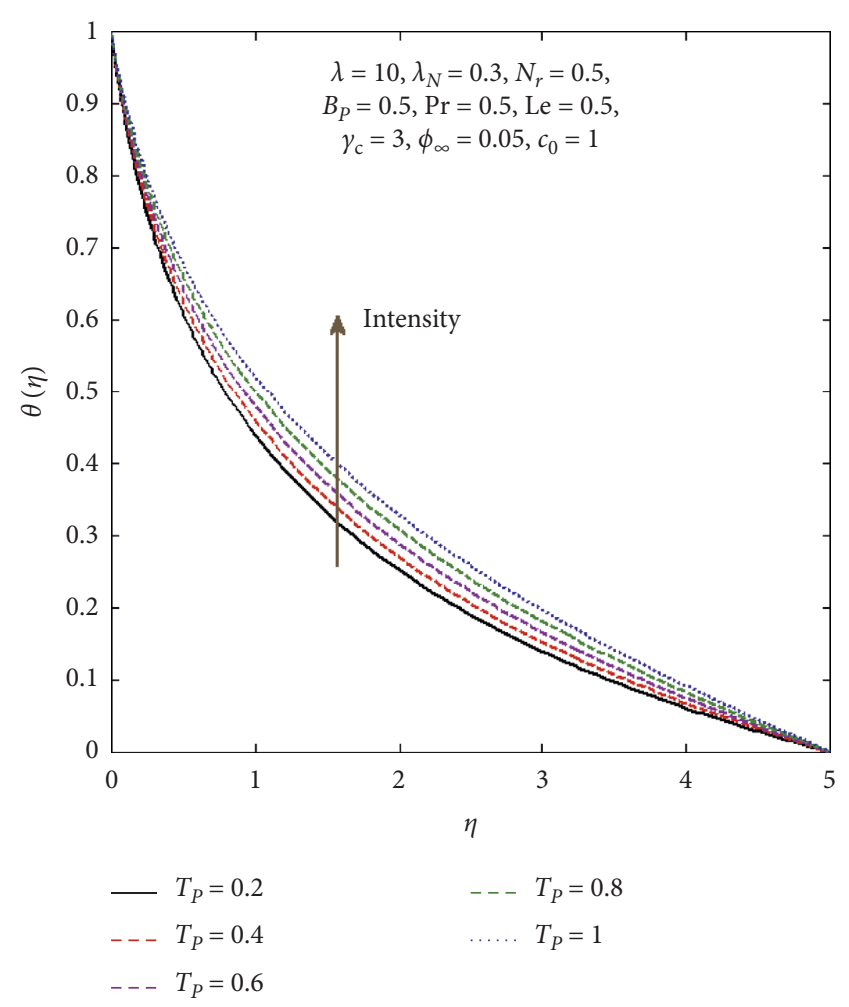

Figure 8: Consequences for $B_{\mathrm{p}}$ on $\theta(\eta)$.

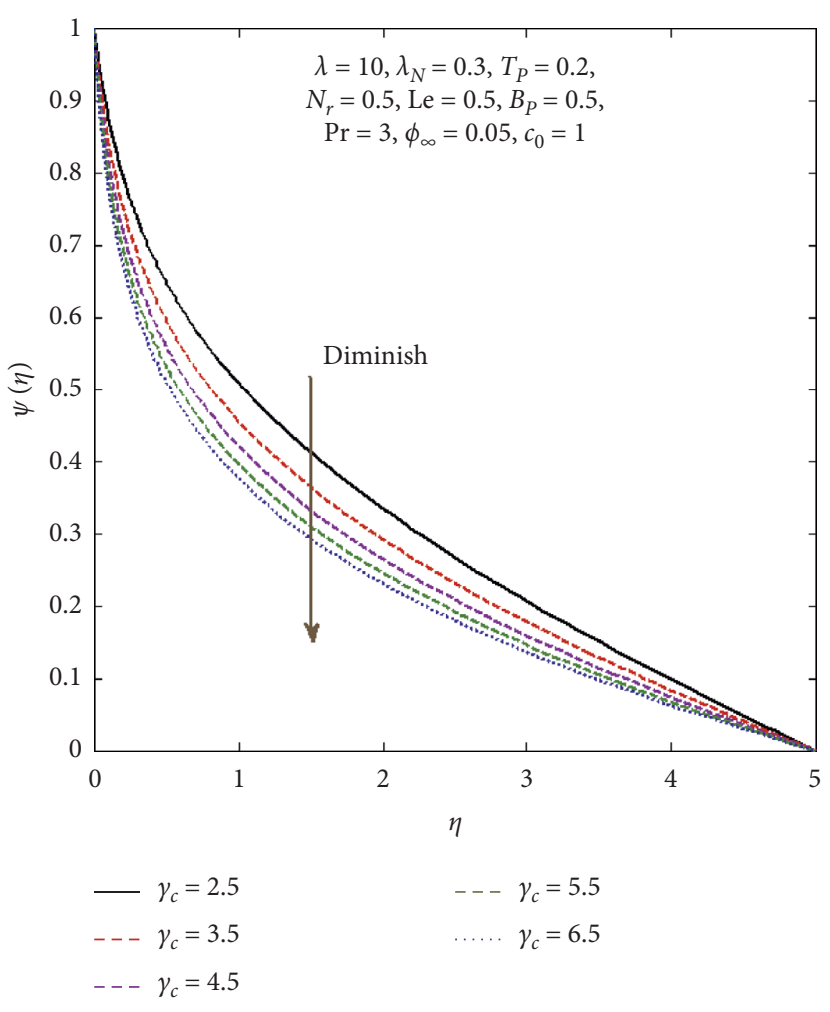

FIgURE 9: Consequences for $\gamma_{\mathrm{c}}$ on $\psi(\eta)$.

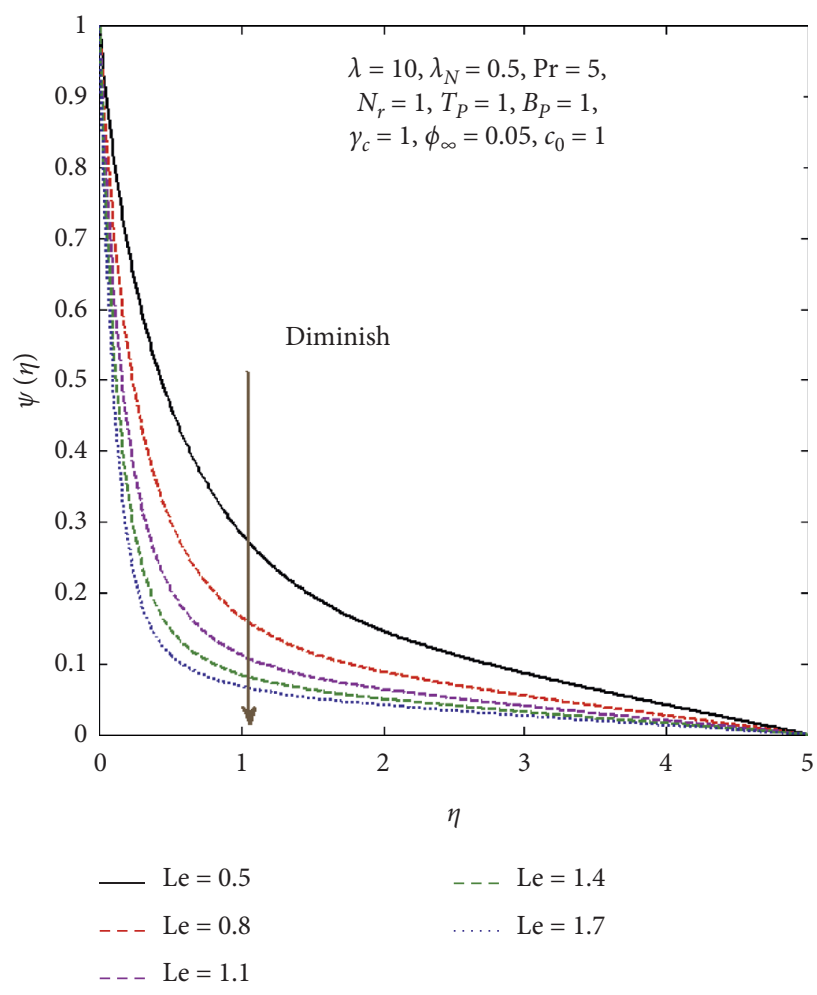

FIgUre 10: Consequences of Lewis number Le. 


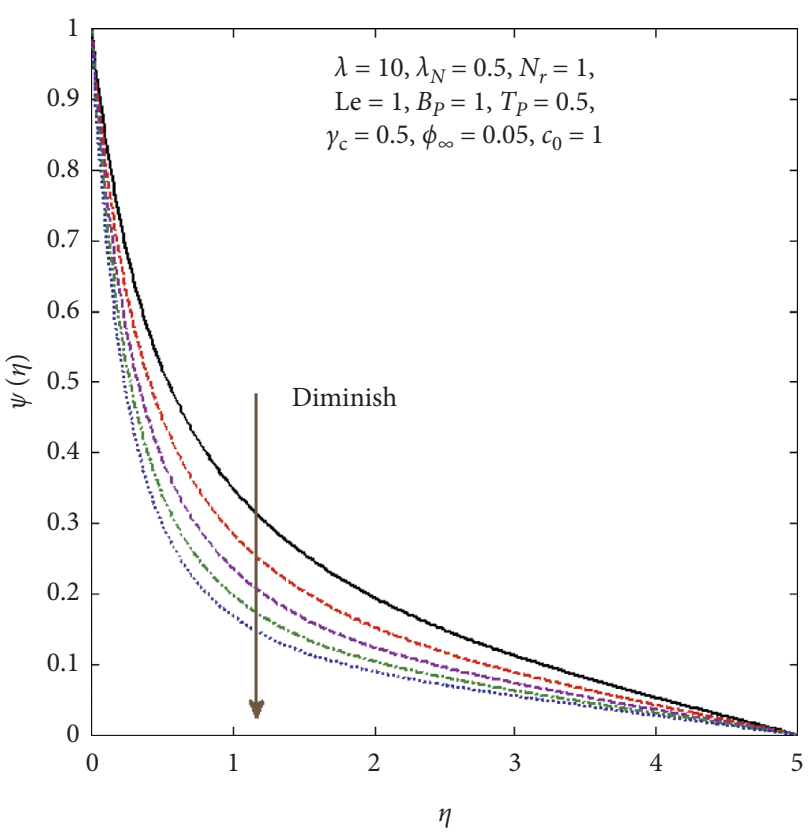

$$
\begin{aligned}
& \text { — } \operatorname{Pr}=2.0 \quad \ldots \quad \operatorname{Pr}=3.5 \\
& \text { _- } \operatorname{Pr}=2.5 \quad \text {..... } P r=4.0 \\
& \text { - - } P r=3.0
\end{aligned}
$$

Figure 11: Consequences of Prandtl number Pr.

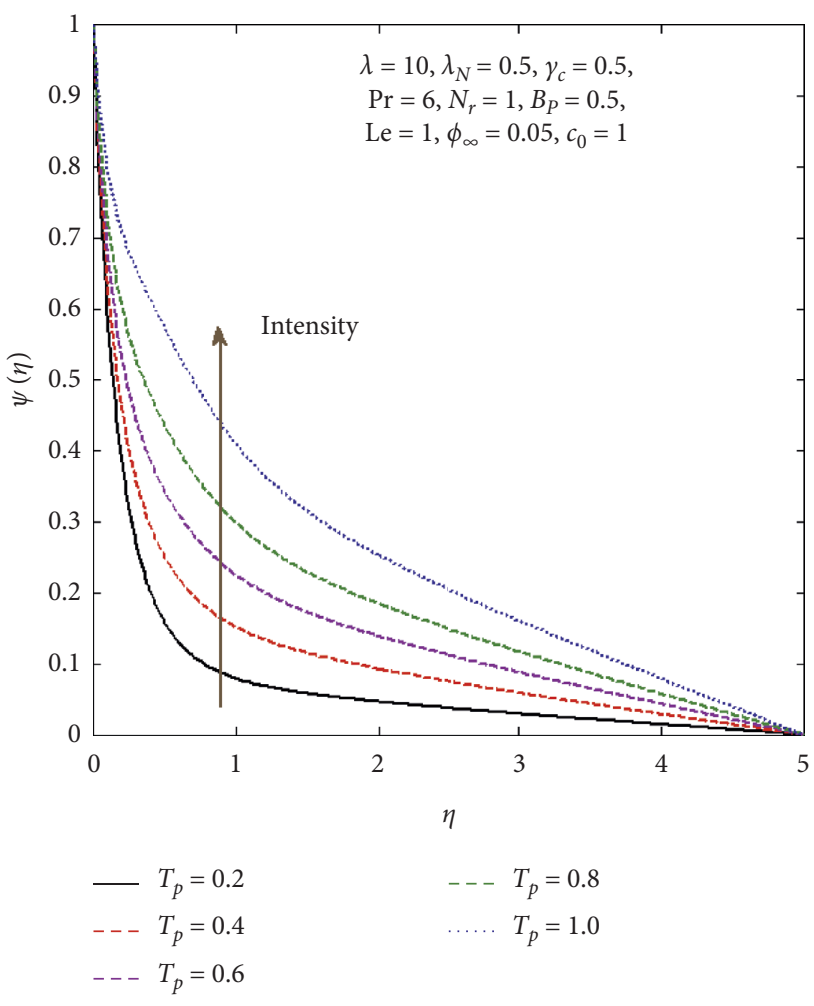

FIGURE 12: Consequences of $T_{\mathrm{p}}$ on $\psi(\eta)$.

transmission of heat. It is inspected that the rate of transmission of heat enhances by increasing $\gamma_{\mathrm{c}}, T_{\mathrm{p}}$, and $\operatorname{Pr}$, while it declines for inclination of $\lambda, B_{\mathrm{p}}$, and Le.

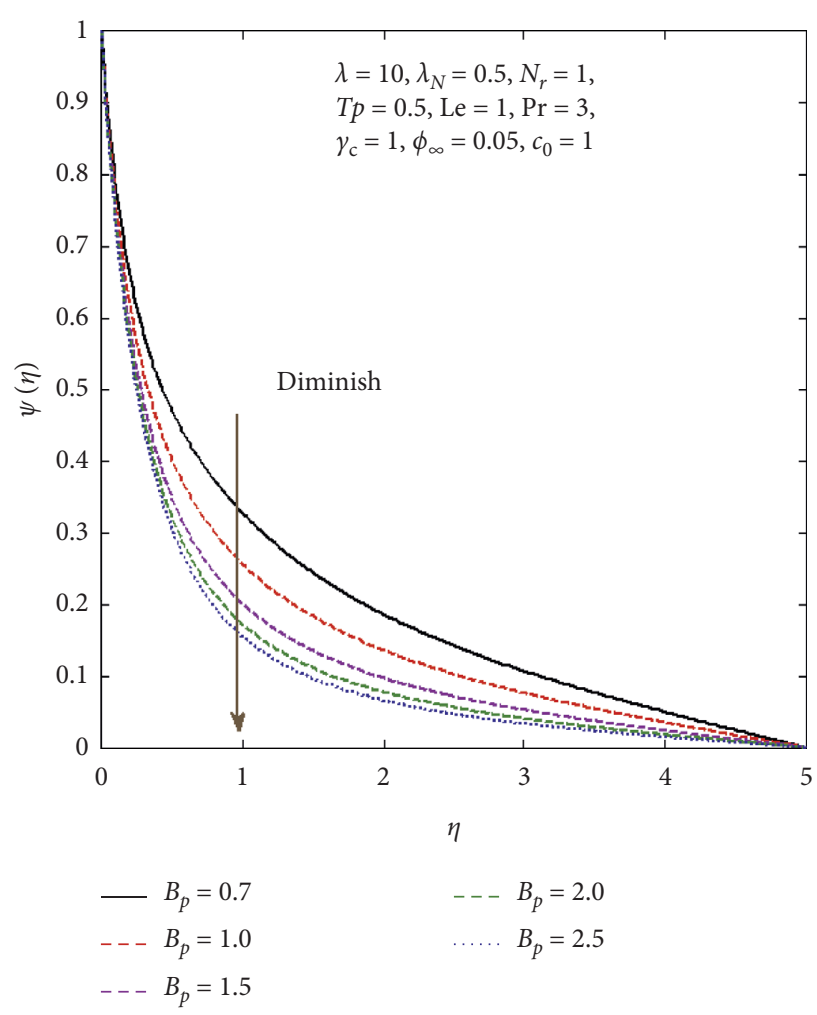

Figure 13: Consequences of $B_{\mathrm{p}}$ on $\psi(\eta)$.

TABLe 1: Numerical values of drag forces $(1 / 2) C_{f} \operatorname{Re}^{(1 / 2)}$

\begin{tabular}{cccccc}
\hline$\gamma_{c}$ & $\lambda$ & $\lambda_{N}$ & $N_{r}$ & $f^{\prime \prime}(0)$ & $(1 / 2) C_{f} \operatorname{Re}^{(1 / 2)}$ \\
\hline 0.1 & 0.1 & 0.1 & 0.1 & 1.7290 & 2.0279 \\
0.2 & - & - & - & 1.7670 & 2.0792 \\
0.3 & - & - & - & 1.8030 & 2.1281 \\
0.4 & - & - & - & 1.8390 & 2.1772 \\
- & 1 & - & - & 1.1340 & 2.4200 \\
- & 2 & - & - & 0.9252 & 2.6372 \\
- & 3 & - & - & 0.8488 & 3.0102 \\
- & 4 & - & - & 0.7853 & 3.2521 \\
- & 1 & 0.1 & - & 1.2290 & 2.7394 \\
- & - & 0.2 & - & 1.2430 & 2.7880 \\
- & - & 0.4 & - & 1.2860 & 2.9398 \\
- & - & 0.7 & - & 1.3510 & 3.1762 \\
0.5 & 3 & 0.1 & 0.1 & 0.9011 & 3.3370 \\
- & - & - & 0.2 & 0.9031 & 3.3499 \\
- & - & - & 0.4 & 0.9067 & 3.3730 \\
- & - & - & 0.7 & 0.9070 & 3.3749 \\
\hline
\end{tabular}

\section{Final Remarks}

This exploration scrutinized the natural convection of Williamson's nanofluid for boundary-layer stagnation point flow over a vertical slender cylinder. Hence, thermophoresis, Brownian motion, natural convection, Williamson's parameter, and curvature parameter are utilized for modelling and analysis. The governing coupled nonlinear ODEs are then solved numerically by using MATLAB technique bvp4c. This research reveals the following outcomes: 
TABle 2: Numerical values of the rate of transmission of heat $\mathrm{Nu} / \mathrm{Re}^{1 / 2}$.

\begin{tabular}{lcccccc}
\hline$\gamma_{c}$ & $\lambda$ & $T_{\mathrm{p}}$ & $B_{\mathrm{p}}$ & $\mathrm{Pr}$ & $\mathrm{Le}$ & $\mathrm{Nu} / \mathrm{Re}^{(1 / 2)}$ \\
\hline 0.1 & 0.1 & 0.1 & 0.1 & 0.3 & 0.4 & 0.8118 \\
0.2 & - & - & - & - & - & 0.8446 \\
0.3 & - & - & - & - & - & 0.8739 \\
- & 0.5 & - & - & - & - & 1.1190 \\
- & 0.7 & - & - & - & - & 0.9200 \\
- & 0.9 & - & - & - & - & 0.8702 \\
- & - & 0.3 & - & - & - & 1.0120 \\
- & - & 0.5 & - & - & - & 1.1430 \\
- & - & 0.7 & - & - & - & 0.7092 \\
- & - & 0.1 & 0.3 & - & - & 0.8221 \\
- & - & - & 0.5 & - & - & 0.7641 \\
- & - & - & 0.7 & - & - & 0.7092 \\
- & - & - & 0.1 & 0.5 & - & 1.1140 \\
- & - & - & - & 0.7 & - & 1.3200 \\
- & - & - & - & 0.9 & - & 1.5120 \\
- & - & - & - & 0.3 & 0.5 & 0.8764 \\
- & - & - & - & - & 0.6 & 0.8700 \\
- & - & - & - & - & 0.8 & 0.8589 \\
\hline
\end{tabular}

(i) The velocity profile is declining due to upsurge in the curvature parameter and Williamson's parameter

(ii) Inclination of the Prandtl number and curvature parameter causes decline in the temperature profile, whereas it is intensified by increments in $\gamma_{c}, B_{\mathrm{p}}$, and $T_{\mathrm{p}}$

(iii) The concentration of nanoparticles is dropped via amplifying Le, Pr, and $B_{\mathrm{p}}$

(iv) The greater value of Williamson's parameter and curvature parameter causes the drag force to increase

(v) Rate of transmission of heat is reduced for larger Williamson's parameter

\section{Data Availability}

The data used to support the findings of this study are included within the article.

\section{Conflicts of Interest}

The authors declare that they have no conflicts of interest.

\section{References}

[1] S. Nadeem, S. Ahmad, N. Muhammad, and M. T. Mustafa, "Chemically reactive species in the flow of a Maxwell fluid," Results in Physics, vol. 7, pp. 2607-2613, 2017.

[2] K. U. Rehman, A. Qaiser, M. Y. Malik, and U. Ali, "Numerical communication for MHD thermally stratified dual convection flow of Casson fluid yields by stretching cylinder," Chinese Journal of Physics, vol. 55, no. 4, pp. 1605-1614, 2017.

[3] M. Hassan, R. Ellahi, A. Zeeshan, and M. M. Bhatti, "Analysis of natural convective flow of non-Newtonian fluid under the effects of nanoparticles of different materials," Proceedings of the Institution of Mechanical Engineers, Part E: Journal of
Process Mechanical Engineering, vol. 233, no. 3, pp. 643-652, 2019.

[4] S. Nadeem, S. Ahmad, and N. Muhammad, "CattaneoChristov flux in the flow of a viscoelastic fluid in the presence of Newtonian heating," Journal of Molecular Liquids, vol. 237, pp. 180-184, 2017.

[5] R. U. Haq, S. Nadeem, N. S. Akbar, and Z. H. Khan, "Buoyancy and radiation effect on stagnation point flow of micropolar nanofluid along a vertically convective stretching surface," IEEE Transactions on Nanotechnology, vol. 14, no. 1, pp. 42-50, 2014.

[6] Z. Ahmed, S. Nadeem, S. Saleem, and R. Ellahi, "Numerical study of unsteady flow and heat transfer CNT-based MHD nanofluid with variable viscosity over a permeable shrinking surface," International Journal of Numerical Methods for Heat \& Fluid Flow, vol. 29, no. 12, pp. 4607-4623, 2019.

[7] M. M. Bhatti, A. Zeeshan, R. Ellahi, O. A. Bég, and A. Kadir, "Effects of coagulation on the two-phase peristaltic pumping of magnetized Prandtl biofluid through an endoscopic annular geometry containing a porous medium," Chinese Journal of Physics, vol. 58, pp. 222-234, 2019.

[8] M. Sheikholeslami, Z. Li, and A. Shafee, "Lorentz forces effect on NEPCM heat transfer during solidification in a porous energy storage system," International Journal of Heat and Mass Transfer, vol. 127, pp. 665-674, 2018.

[9] N. Ijaz, M. Bhatti, and A. Zeeshan, "Heat transfer analysis in magnetohydrodynamic flow of solid particles in non-Newtonian ree-eyring fluid due to peristaltic wave in a channel," Thermal Science, vol. 23, no. 2, pp. 1017-1026, 2019.

[10] N. S. Akbar, S. Nadeem, R. Ul Haq, and Z. H. Khan, "Radiation effects on MHD stagnation point flow of nano fluid towards a stretching surface with convective boundary condition," Chinese Journal of Aeronautics, vol. 26, no. 6, pp. 1389-1397, 2013.

[11] R. Ellahi, A. Zeeshan, F. Hussain, and T. Abbas, "Thermally charged MHD bi-phase flow coatings with non-Newtonian nanofluid and hafnium particles along slippery walls," Coatings, vol. 9, no. 5, p. 300, 2019.

[12] A. Zeeshan, N. Ijaz, T. Abbas, and R. Ellahi, "The sustainable characteristic of bio-bi-phase flow of peristaltic transport of MHD Jeffrey fluid in the human body," Sustainability, vol. 10, no. 8, p. 2671, 2018.

[13] F. U. Rehman, S. Nadeem, H. U. Rehman, and R. U. Haq, "Thermophysical analysis for three-dimensional MHD stagnation-point flow of nanomaterial influenced by an exponential stretching surface," Results in Physics, vol. 8, pp. 316-323, 2018.

[14] K. Parand, M. Fotouhifar, H. Yousefi, and M. Delkhosh, “A rational approximation to the boundary layer flow of a nonNewtonian fluid," Journal of the Brazilian Society of Mechanical Sciences and Engineering, vol. 41, no. 3, p. 125, 2019.

[15] M. F. Javed, M. I. Khan, N. B. Khan et al., "Axisymmetric flow of Casson fluid by a swirling cylinder," Results in Physics, vol. 9, pp. 1250-1255, 2018.

[16] A. Rehman, S. Nadeem, and M. Y. Malik, "Boundary layer stagnation-point flow of a third grade fluid over an exponentially stretching sheet," Brazilian Journal of Chemical Engineering, vol. 30, no. 3, pp. 611-618, 2013.

[17] M. Y. Malik, M. Bibi, F. Khan, and T. Salahuddin, "Numerical solution of Williamson fluid flow past a stretching cylinder and heat transfer with variable thermal conductivity and heat generation/absorption," AIP Advances, vol. 6, no. 3, Article ID 035101, 2016. 
[18] S. U. Choi and J. A. Eastman, "Enhancing Thermal Conductivity of Fluids with Nanoparticles," Argonne National Lab., Lemont, IL, USA, No. ANL/MSD/CP-84938; CONF951135-29, 1995.

[19] J. Buongiorno, "Convective transport in nanofluids," 2006.

[20] S. K. Das, S. U. Choi, W. Yu, and T. Pradeep, Nanofluids: Science and Technology, John Wiley \& Sons, Hoboken, NJ, USA, 2007.

[21] C. Zhang, L. Zheng, X. Zhang, and G. Chen, "MHD flow and radiation heat transfer of nanofluids in porous media with variable surface heat flux and chemical reaction," Applied Mathematical Modelling, vol. 39, no. 1, pp. 165-181, 2015.

[22] N. Muhammad, S. Nadeem, and R. U. Haq, "Heat transport phenomenon in the ferromagnetic fluid over a stretching sheet with thermal stratification," Results in Physics, vol. 7, pp. 854-861, 2017.

[23] S. Saini and Y. D. Sharma, "Double-diffusive bioconvection in a suspension of gyrotactic microorganisms saturated by nanofluid," Journal of Applied Fluid Mechanics, vol. 12, no. 1, 2019.

[24] M. Safaei, G. Ahmadi, M. Goodarzi, M. Safdari Shadloo, H. Goshayeshi, and M. Dahari, "Heat transfer and pressure drop in fully developed turbulent flows of graphene nanoplatelets-silver/water nanofluids," Fluids, vol. 1, no. 3, p. 20, 2016.

[25] M. M. Rashidi, M. Nasiri, M. S. Shadloo, and Z. Yang, "Entropy generation in a circular tube heat exchanger using nanofluids: effects of different modeling approaches," Heat Transfer Engineering, vol. 38, no. 9, pp. 853-866, 2017.

[26] M. Goodarzi, A. Amiri, M. S. Goodarzi et al., "Investigation of heat transfer and pressure drop of a counter flow corrugated plate heat exchanger using MWCNT based nanofluids," International Communications in Heat and Mass Transfer, vol. 66, pp. 172-179, 2015.

[27] E. Abedini, T. Zarei, H. Rajabnia, R. Kalbasi, and M. Afrand, "Numerical investigation of vapor volume fraction in subcooled flow boiling of a nanofluid," Journal of Molecular Liquids, vol. 238, pp. 281-289, 2017.

[28] M. Afrand, E. Abedini, and H. Teimouri, "Experimental investigation and simulation of flow boiling of nanofluids in different flow directions," Physica E: Low-Dimensional Systems and Nanostructures, vol. 87, pp. 248-253, 2017.

[29] R. V. Williamson, "The flow of pseudoplastic materials," Industrial \& Engineering Chemistry, vol. 21, no. 11, pp. 1108-1111, 1929.

[30] M. Ramzan, M. Bilal, and J. D. Chung, "MHD stagnation point Cattaneo-Christov heat flux in Williamson fluid flow with homogeneous-heterogeneous reactions and convective boundary condition-a numerical approach," Journal of Molecular Liquids, vol. 225, pp. 856-862, 2017.

[31] Z. Shah, E. Bonyah, S. Islam, W. Khan, and M. Ishaq, "Radiative MHD thin film flow of Williamson fluid over an unsteady permeable stretching sheet," Heliyon, vol. 4, no. 10, e00825 pages, 2018.

[32] R. A. Seban and R. Bond, "Skin-friction and heat-transfer characteristics of a laminar boundary layer on a cylinder in axial incompressible flow," Journal of the Aeronautical Sciences, vol. 18, no. 10, pp. 671-675, 1951.

[33] A. Mucoglu and T. S. Chen, "Buoyancy effects on forced convection along a vertical cylinder with uniform surface heat flux," Journal of Heat Transfer, vol. 98, no. 3, pp. 523-525, 1976.

[34] S. Nadeem, A. Rehman, and M. E. Ali, "The boundary layer flow and heat transfer of a nanofluid over a vertical, slender cylinder," Proceedings of the Institution of Mechanical Engineers, Part N: Journal of Nanoengineering and Nanosystems, vol. 226, no. 4, pp. 165-173, 2012.

[35] P. M. Patil, A. Shashikant, and P. S. Hiremath, "Effects of surface roughness on mixed convection nanoliquid flow over slender cylinder with liquid hydrogen diffusion," International Journal of Hydrogen Energy, vol. 44, no. 21, pp. 11121-11133, 2019.

[36] G. J. Reddy, B. Kethireddy, J. C. Umavathi, and M. A. Sheremet, "Heat flow visualization for unsteady Casson fluid past a vertical slender hollow cylinder," Thermal Science and Engineering Progress, vol. 5, pp. 172-181, 2018.

[37] G. J. Reddy, B. Kethireddy, and O. A. Beg, "Flow visualization using heat lines for unsteady radiative hydromagnetic micropolar convection from a vertical slender hollow cylinder," International Journal of Mechanical Sciences, vol. 140, pp. $493-505,2018$.

[38] B. Mallikarjuna, A. M. Rashad, A. Chamkha, and M. M. M. Abdou, "Mixed bioconvection flow of a nanofluid containing gyrotactic microorganisms past a vertical slender cylinder," Frontiers in Heat and Mass Transfer (FHMT), vol. 10, 2018

[39] G. J. Reddy, B. Kethireddy, M. Kumar, and H. P. Rani, "Entropy generation for transient Casson fluid past a vertical cylinder with Bejan's flow visualization," International Journal for Computational Methods in Engineering Science and Mechanics, vol. 20, no. 3, pp. 175-200, 2019.

[40] W. Xu, A. Cheng, Y. Ma, and X. Gao, "Multi-mode flowinduced vibrations of two side-by-side slender flexible cylinders in a uniform flow," Marine Structures, vol. 57, pp. 219-236, 2018.

[41] T. Li, N. Pintus, and G. Viglialoro, "Properties of solutions to porous medium problems with different sources and boundary conditions," Zeitschrift für angewandte Mathematik und Physik, vol. 70, no. 3, p. 86, 2019.

[42] R. Shah and T. Li, "The thermal and laminar boundary layer flow over prolate and oblate spheroids," International Journal of Heat and Mass Transfer, vol. 121, pp. 607-619, 2018. 